\title{
Sustainable Sandwich Panels Made of Aluminium Skins and Bamboo Rings
}

\author{
Lívia Avila de Oliveira ${ }^{a, b}$, Jacob Nicholas Orth ${ }^{c}$, Rodrigo Teixeira Santos Freire ${ }^{a, b}$ (1), \\ Túlio Hallak Panzera ${ }^{a, b^{*}}$ (D), André Luis Christoforo ${ }^{d}$, Fabrizio Scarpa ${ }^{e}$ \\ ${ }^{a}$ Universidade Federal de São João del Rei (UFSJ), Departamento de Engenharia Mecânica e Produção, \\ Centro de Inovação e Tecnologia em Materiais Compósitos (CIT ${ }^{C}$ C), São João del-Rei, MG, Brasil \\ ${ }^{b}$ Universidade Federal de São João del Rei (UFSJ), Departamento de Ciências Naturais, São João del- \\ Rei, MG, Brasil \\ 'Texas Tech University, Department of Mechanical Engineering, Lubbock, Texas, USA \\ ${ }^{d}$ Universidade Federal de São Carlos, Departamento de Engenharia Civil, São Carlos, SP, Brasil \\ ${ }^{e}$ University of Bristol, Bristol Composites Institute (ACCIS), BS8 1TR Bristol, UK
}

Received: November 30, 2020; Revised: March 24, 2021; Accepted: May 06, 2021

\begin{abstract}
This work investigates the mechanical behaviour of a sustainable sandwich panel, consisting of bamboo rings core, treated aluminium skins and epoxy adhesive. A Design of Experiment (DoE) is used to identify the effects of bamboo diameters $(30$ and $45 \mathrm{~mm}$ ) and aluminium skin treatments (alkaline degreasing and application of primer) on the mechanical and physical properties of sandwich panels. The aluminium skins treated with the wash primer significantly increase adhesion to the polymer, resulting in greater maximum load, flexural strength, maximum skin stress and maximum core shear stress; while the skins treated with $\mathrm{NaOH}$ resulted in a greater flexural and core shear modulus. Relatively more rigid and resistant structures are obtained with $\varnothing 30 \mathrm{~mm}$ rings, due to the increased surface contact area and the number of constraints on the core. The samples fail due to the skin fracture, implying an efficient face-core bond that is attributed to the proper absorption of the polymer by bamboo and the treatment of the aluminium surface. The proposed panels present good mechanical performance, proving to be a feasible and promising alternative for secondary structural applications.
\end{abstract}

Keywords: Bamboo rings, Sandwich panels, Design of Experiment, Aluminium surface treatment, Mechanical properties.

\section{Introduction}

Lightweight structures have been widely used in highperformance applications such as aerospace, automotive, civil engineering and many other fields in recent decades ${ }^{1}$. Sandwich structures have also gained much attention due to their excellent mechanical performance and outstanding energy absorption properties ${ }^{2-4}$. Sandwich panels are lightweight structures, typically composed of two thin sheets of stiff and strong material, separated by a thick core of low-density material ${ }^{5-7}$. The optimal design of a sandwich panel has been a challenge since the designer can tailor the composite properties by adjusting its constituents and geometrical parameters ${ }^{5,6,8}$. Among the huge variety of parameters, the core and face constituents, core geometry and core/face adhesion are widely considered.

The skins are generally made of metal sheets (aluminium or steel), fibre-reinforced laminates, plywood and others, while the core is made of resin-impregnated paper, reinforced polymers, polymeric and metallic foams, perforated chipboard and lightweight concrete ${ }^{1,9}$. The core can have many different shapes ${ }^{10}$, including honeycomb structures, foams, corrugated plates and new lattices ${ }^{11}$, such as auxetic honeycomb structures ${ }^{12,13}$, egg-box-like core ${ }^{14}$ and truss

*e-mail: panzera@ufsj.edu.br core ${ }^{15}$. Hexagonal honeycombs are the most common cellular cores used in structural applications ${ }^{16}$. However, circular cell honeycombs, arranged in different packing geometries (cubic, hexagonal and orthotropic), have recently been proposed as a very promising core topology to improve the rigidity and strength of sandwich panels ${ }^{17-19}$.

The skin-core bonding is critical for sandwich panels, as the adhesive layer must ensure an efficient skin-core load transfer. The improvement of structural stiffness can be achieved by controlling the amount of adhesive or applying surface treatments to the skins, especially when considering metallic surfaces ${ }^{20}$. Epoxy polymers are the most common type of structural adhesive, providing relatively high modulus and strength to the structure ${ }^{21}$.

In the last decades, unbridled population growth has led to high production and consumption of materials, causing accumulation of waste and depletion of resources. Thus, another challenge for materials scientists and engineers is not only to develop efficient and cost-effective products, but also to keep evolving technologically without compromising the availability of resources for future generations $\mathrm{s}^{22}$. More research is needed to reduce the environmental impact of disposing of materials that use natural and biodegradable resources in high-end quality sustainable industrial products. 
In this context, bamboo can be exploited for the design and development of composite materials due to its intrinsic characteristics, such as high renewability, biodegradability, versatility, rapid growth, low weight, low cost and, especially, for its physical and mechanical properties that already meet engineering requirements for use in civil construction ${ }^{23-26}$.

Bamboos are giant grass-like plants, abundant in tropical and subtropical regions such as Latin America and southeastern Asia. More than 1500 different species are available worldwide and their chemical composition varies widely from species to species ${ }^{27,28}$. For most woody species, the bamboo structure is composed of cylindrical shell culms with solid transverse diaphragms or "nodes" that separate hollow inter-nodal regions along with their height ${ }^{29}$. The circular cross-section is composed of unidirectional cellulosic fibres oriented parallel to the longitudinal axis of the culm embedded in a lignin matrix ${ }^{29}$.

Bamboo can be an alternative material for the development of structural biocomposites for everyday use, such as prefabricated wall panels ${ }^{30}$, sports equipment ${ }^{31}$, lightweight car components ${ }^{32}$ and others. Recently, the use of bamboo rings as a circular core in sandwich panels for structural applications has been investigated experimentally ${ }^{33}$ and numerically ${ }^{34}$. Hartoni et al..$^{33}$ performed bending tests on sandwich composites made with bamboo core and plywood skins, varying the thickness of the skin and panel. Meanwhile, Darzi et al. ${ }^{34}$ conducted numerical studies on the flexural capacity of ultralight composite sandwich panels made of plywood faces and bamboo core. Both studies revealed promising features for structural applications according to the properties of bamboo sandwich composites.

To the best of the author's knowledge, this is the first attempt to investigate the flexural behaviour of sandwich panels made from bamboo rings core, treated aluminium skins and epoxy adhesive. A statistical design is carried out to identify the effects of the factors: aluminium treatment (alkaline degreasing and primer application) and bamboo

Table 1. Full Factorial Design $\left(2^{2}\right)$.

\begin{tabular}{ccc}
\hline $\begin{array}{c}\text { Experimental } \\
\text { Condition }\end{array}$ & $\begin{array}{c}\text { Aluminium } \\
\text { Treatment }\end{array}$ & Bamboo Diameter \\
\hline 1 & $\mathrm{NaOH}$ & $30 \mathrm{~mm}$ \\
\hline 2 & $\mathrm{NaOH}$ & $45 \mathrm{~mm}$ \\
\hline 3 & Wash Primer & $30 \mathrm{~mm}$ \\
\hline 4 & Wash Primer & $45 \mathrm{~mm}$ \\
\hline
\end{tabular}
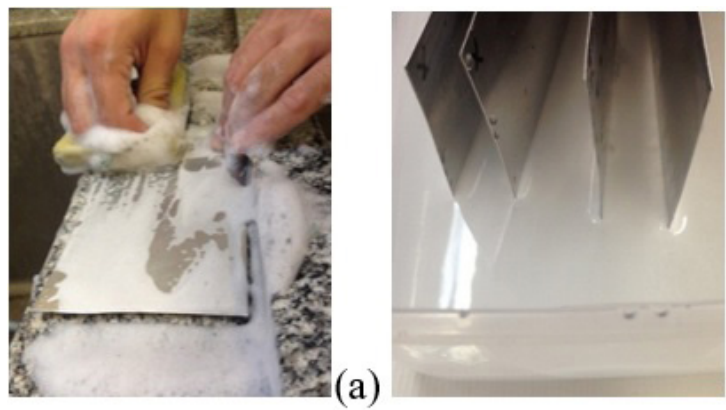

(b)
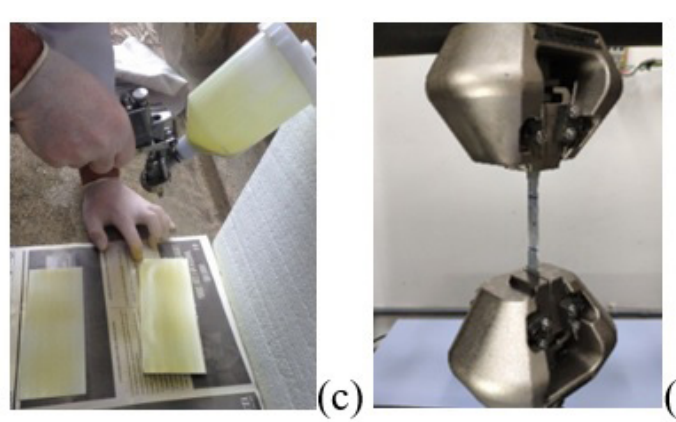

(d)

diameter (30 and $40 \mathrm{~mm}$ ), on the physical and mechanical properties of the panel. Failure analysis and a comparison study with another type of core are also evaluated to investigate the feasibility of the proposed panel for secondary structural applications.

\section{Materials and Methods}

\subsection{Materials}

The sandwich panels consist of a pair of treated-aluminium sheets as skins, bamboo rings as a core and epoxy polymer as an adhesive. The brushed aluminium casting alloy sheets of $0.5 \mathrm{~mm}$ thickness are sourced from Alumiaço (Brazil). Sodium hydroxide $(\mathrm{NaOH}, 97.5 \%)$ from Sulfal Química (Brazil) and wash primer (bicomponent: 045 / 051) from Sherwin Williams are used to treat aluminium surfaces for better adhesion. The wash primer is a combination of vinyl, epoxy, phenolic resins, mineral fillers, anti-corrosive organic and inorganic pigments, hydrocarbons aromatics and acetates $^{35}$. Bamboo culms belong to the Bambusa tuldoides species and are harvested at the Federal University of São João del-Rei (Brazil, 21ํㅇ'26.5”S 4415'41.3”W). The epoxy resin Renlam M and the Aradur HY951 hardener, supplied by Huntsman, are used as a core-face adhesive.

\subsection{Statistical analysis}

A Full Factorial Design $\left(2^{2}\right)$ is established to investigate the effect of the factors (levels), aluminium surface treatment $(\mathrm{NaOH}$ / Wash Primer) and the bamboo diameter $(30 \mathrm{~mm} / 45 \mathrm{~mm})$ on the mechanical and physical properties of sandwich panels, providing 4 experimental conditions as shown in Table 1. A constant cubic packing geometry of bamboo rings is considered for the core design. Three specimens are fabricated for each experimental condition with two replicates, running a total of 24 panels. Analysis of Variance (ANOVA) is used to assess the significance of each experimental factor and/or interaction within a $95 \%$ confidence interval. Minitab v. 18 software is used to manipulate the data.

\subsection{Aluminium treatment}

Aluminium sheets are cut according to the sandwich panel dimensions, that is, $90 \times 240 \mathrm{~mm}^{2}$ and $90 \times 225 \mathrm{~mm}^{2}$, for $\varnothing 30$ and $\varnothing 45 \mathrm{~mm}$ bamboo rings, respectively. The skins are degreased with an ordinary detergent and water-rinsed (Figure 1a), cleaned with acetone to remove remaining dirt

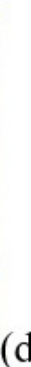

Figure 1. Aluminium treatment: (a) degreasing of the skins, (b) immersion in the $\mathrm{NaOH}$ solution, (c) pulverization with wash primer

and (d) tensile test. 
and dried with a gun dryer. Half of the clean aluminium skins are immersed in a $5 \mathrm{wt} . \%$ solution of sodium hydroxide (Figure 1b) at room temperature for 1 minute and then rinsed with water. The skins are dried and placed on a plastic film to prevent moisture absorption until the sandwich panels are manufactured. The pre-primer solution is prepared by adding two parts of Wash Primer 045 to one part of catalyst (051) and then spraying onto the other half of the skins (Figure 1c). After 20 minutes of pre-primer curing, the skins are immediately used in the manufacture of sandwich panels. Ten aluminium specimens without treatment are tested under tensile loads according to ASTM E8/E8M-16a ${ }^{36}$ (Figure 1d) to better assess the properties of the sandwich panels. The tests are performed at $2 \mathrm{~mm} / \mathrm{min}$ on a $100 \mathrm{kN}$ Shimadzu AG-X Plus test machine equipped with video extensometer.

\subsection{Bamboo preparation}

Bamboo culms approximately 3-years-old (Figure 2a) are harvested during the waning moon and left upright for three weeks to drain the starch present internally and to stabilize radial shrinkage. The bamboo rings are cut by a bandsaw at different heights, $13 \mathrm{~mm}$ (rings for sandwich panels, Figure 2b) and 60 or $90 \mathrm{~mm}$ (rings for compression test height is twice the outer diameter, Figure 2c). Subsequently, the rings are oven-dried at $50^{\circ} \mathrm{C}$ for three days for complete drying and left 24 hours at room temperature $\left(23^{\circ} \mathrm{C}\right.$ and $55 \%$ of relative humidity) to reach the equilibrium moisture content. Fifteen dried bamboo rings of each diameter are characterised by compression (Figure $2 \mathrm{~d}$ ) and density tests following ISO $22157-1^{37}$ and ISO $22157-2^{38}$. The tests are performed at $2 \mathrm{~mm} / \mathrm{min}$ on a $100 \mathrm{kN}$ Shimadzu AG-X Plus test machine. Due to the curvature and surface of the bamboo, the tests are conducted without video extensometer; deformation was calculated based on the crosshead displacement. The strength is determined by the maximum load applied to the cross-sectional area of the hollow tube, i.e., considering the outer and inner diameter.

\subsection{Manufacture and characterization of sandwich panel}

The manufacture of the sandwich panel begins by inserting the treated aluminium skins into a wooden mould covered with an Armalon ${ }^{\circledR}$ release tape to prevent leakage (Figure 3a). The epoxy system (10:1 resin/hardener) is hand-mixed for 5 minutes and poured uniformly into the mould, considering approximately $1 \mathrm{~mm}$ thick. Bamboo rings, previously selected to avoid height variation $(13 \mathrm{~mm} \pm 0.05)$, are then placed on the skin according to the experimental condition, i.e. $\varnothing 30$ or $\varnothing 45 \mathrm{~mm}$ (Figure 3b). The mould is closed with a wooden lid and compacted with a cold uniaxial pressure of $2.3 \mathrm{kPa}$ for $24 \mathrm{~h}$ at room temperature (Figure $3 \mathrm{c}$ ). Subsequently, the material (Figure 3d) is demoulded and the second skin is bonded following the same process, resulting in a sandwich panel approximately $15 \mathrm{~mm}$ thick (Figure 3e). The panel is cured for 7 days at room temperature $\left(22 \pm 2^{\circ} \mathrm{C}\right)$ before testing.

The sandwich panels are characterised by three-point bending test (Figure 3f). A 100kN Shimadzu AG-X Plus test machine is used, considering a crosshead speed of $6 \mathrm{~mm} / \mathrm{min}$ and a span length of $150 \mathrm{~mm}$. The maximum load, flexural strength and modulus are determined based on ASTM D790 ${ }^{39}$, considering the panel as a solid and homogenous material. The skin stress is calculated based on ASTM C $393^{40}$, while the core shear stress and modulus responses are based on standard bending theory ${ }^{9}$ and ASTM D $7250^{41}$. The equivalent density of the sandwich panels is also assessed by measuring the dimensions and mass of the panels using a calliper $(0.01 \mathrm{~mm})$ and a precision scale $(0.001 \mathrm{~g})$.

\section{Results and Discussion}

\subsection{Individual phases}

Table 2 shows the mechanical and physical properties of the aluminium sheets and bamboo rings of both diameters
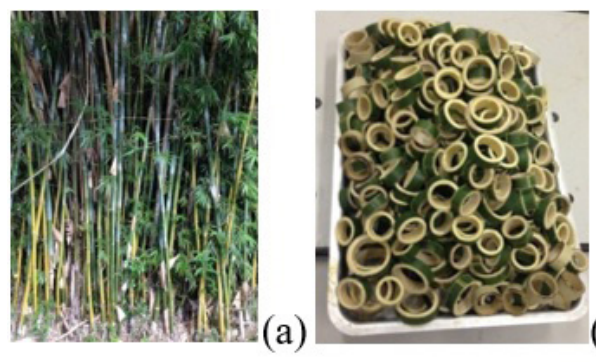

(a)

(b)
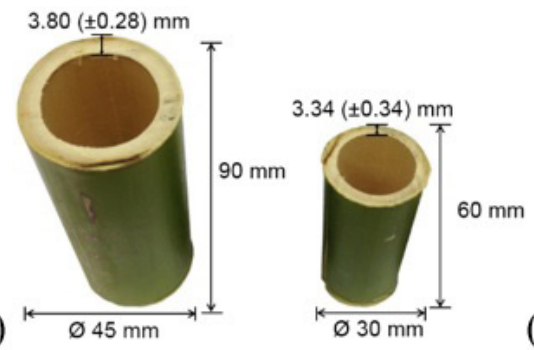

(c)

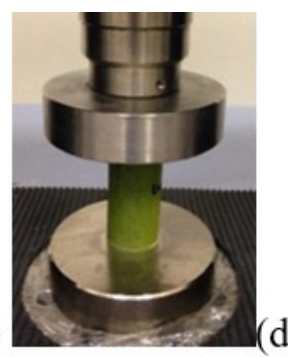

(d)

Figure 2. (a) Bamboo culms, (b) bamboo rings, (c) bamboo samples for (d) compression test.

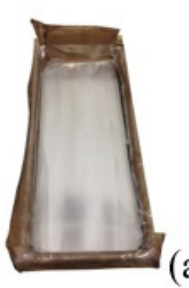

(a)

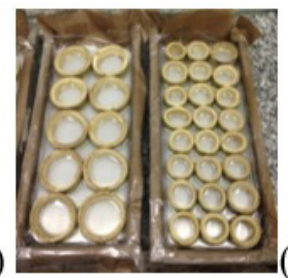

(b)

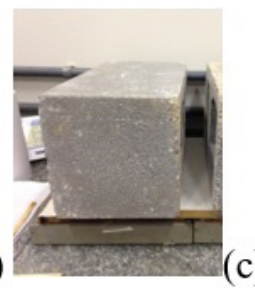

(c)

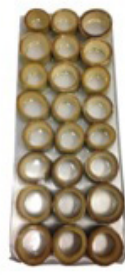

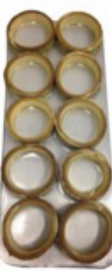

(d)
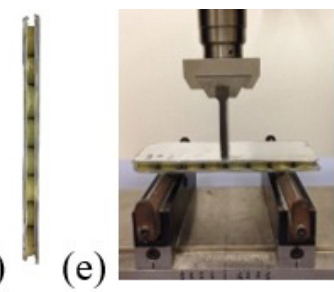

Figure 3. Manufacturing steps: (a) mould preparation, (b) bamboo ring insertion, (c) cold compaction, (d) second layer bonding, (e) sandwich panel and (f) bending test. 
Table 2. Mechanical and physical results of the panel constituents.

\begin{tabular}{|c|c|c|c|c|c|}
\hline \multirow{2}{*}{ Material } & \multicolumn{2}{|c|}{ Tensile } & \multicolumn{2}{|c|}{ Compressive } & \multirow{2}{*}{$\begin{array}{l}\text { Physical } \\
\rho\left[\mathrm{g} / \mathrm{cm}^{3}\right]\end{array}$} \\
\hline & $\sigma_{\max }[\mathrm{MPa}]$ & $\mathrm{E}_{\mathrm{T}}[\mathrm{GPa}]$ & $\sigma_{\max }[\mathrm{MPa}]$ & $\mathrm{E}_{\mathrm{C}}[\mathrm{GPa}]$ & \\
\hline Brushed aluminium & $103.5( \pm 7.6)$ & $35.3( \pm 4.9)$ & - & - & $2.7 *$ \\
\hline Bamboo ring $\varnothing 30 \mathrm{~mm}$ & - & - & $148.7( \pm 16.4)$ & $12.1( \pm 0.7)$ & $0.85( \pm 0.02)$ \\
\hline Bamboo ring $\varnothing 45 \mathrm{~mm}$ & - & - & $142.1( \pm 19.5)$ & $12.1( \pm 0.6)$ & $0.79( \pm 0.03)$ \\
\hline
\end{tabular}

Table 3. Mean and standard deviation values for DoE responses.

\begin{tabular}{cccccccc}
\hline E.C. & $\begin{array}{c}\text { Equivalent } \\
\text { Density }\left(\mathrm{g} / \mathrm{cm}^{3}\right)\end{array}$ & $\begin{array}{c}\text { Maximum Load } \\
(\mathrm{N})\end{array}$ & $\begin{array}{c}\text { Flexural } \\
\text { Strength }(\mathrm{MPa})\end{array}$ & $\begin{array}{c}\text { Flexural } \\
\text { Modulus }(\mathrm{MPa})\end{array}$ & $\begin{array}{c}\text { Skin Stress } \\
(\mathrm{MPa})\end{array}$ & $\begin{array}{c}\text { Core Shear } \\
\text { Stress }(\mathrm{MPa})\end{array}$ & $\begin{array}{c}\text { Core Shear } \\
\text { Modulus }(\mathrm{MPa})\end{array}$ \\
\hline $\mathrm{R} 1$ & $0.616( \pm 0.012)$ & $2835.7( \pm 175.8)$ & $29.92( \pm 3.84)$ & $6.41( \pm 0.04)$ & $160.43( \pm 0.08)$ & $2.74( \pm 0.56)$ & $93.67( \pm 4.01)$ \\
\cline { 2 - 8 } $\mathrm{R} 1$ & $0.609( \pm 0.009)$ & $2610.7( \pm 207.0)$ & $28.36( \pm 1.09)$ & $6.56( \pm 0.31)$ & $153.96( \pm 25.25)$ & $2.47( \pm 0.05)$ & $77.70( \pm 13.56)$ \\
\cline { 2 - 9 } & $0.618( \pm 0.018)$ & $3172.0( \pm 138.8)$ & $33.85( \pm 1.11)$ & $5.86( \pm 0.06)$ & $176.02( \pm 5.50)$ & $3.12( \pm 0.10)$ & $88.33( \pm 10.00)$ \\
\hline & $0.601( \pm 0.013)$ & $2857.6( \pm 336.1)$ & $30.93( \pm 1.01)$ & $5.04( \pm 0.08)$ & $165.31( \pm 18.40)$ & $2.93( \pm 0.33)$ & $64.44( \pm 5.93)$ \\
\hline $\mathrm{R} 2$ & $0.613( \pm 0.012)$ & $2728.1( \pm 152.1)$ & $30.71( \pm 2.41)$ & $6.65( \pm 0.25)$ & $163.94( \pm 18.44)$ & $2.77( \pm 0.16)$ & $91.67( \pm 7.17)$ \\
\hline & $0.610( \pm 0.025)$ & $2683.6( \pm 289.9)$ & $27.76( \pm 13.03)$ & $6.41( \pm 0.15)$ & $159.04( \pm 27.43)$ & $2.39( \pm 0.38)$ & $73.93( \pm 13.99)$ \\
\hline
\end{tabular}

Table 4. Additional characteristics of sandwich panels.

\begin{tabular}{ccccc}
\hline Material type & Bamboo rings per panel & $\begin{array}{c}\text { Surface contact area } \\
\left(\mathrm{mm}^{2}\right)\end{array}$ & Voids (\%) & $\begin{array}{c}\text { Core configuration } \\
\text { (where force is applied) }\end{array}$ \\
\hline Sandwich panel Ø30 mm & 24 & 11745.35 & 45.62 \\
\hline Sandwich panel Ø45 mm & 10 & 8929.66 & 55.90 \\
\hline
\end{tabular}

investigated. The brushed aluminium sheet exhibits an ultimate tensile strength and modulus of 103.5 $\mathrm{MPa}$ and $35.3 \mathrm{GPa}$, respectively. Figure 4 shows a typical stress versus strain curve. This behaviour, also observed by ${ }^{42,43}$, corresponds to an aluminium casting alloy with additions that lead to less mechanical strength and stiffness, but greater elongation. The compressive moduli of both diameters are similar. However, the compressive strength and equivalent density show higher results for bamboo rings of smaller diameter (Ø30 mm). According to Krause et al. ${ }^{25}$, the increase in density occurs mainly due to a combination of fibre volume fraction increment and voids volume fraction decrement, and the relationship between the increase in strength and the variation in density is almost linear. Therefore, these smaller bamboo rings, located higher above the culm, show a reduction in the number and size of the vascular bundles with a consequent increase in the fibre volume fraction, resulting in superior properties ${ }^{44}$.

\subsection{Sandwich panel}

Table 3 presents the mean values and standard deviation of each replicate for the sandwich panel responses, which are statistically interpreted in Section 3.3.

Table 4 shows the additional characteristics of the sandwich panels. Twenty-four (24) bamboo rings of $\varnothing 30 \mathrm{~mm}$ are used in E.C. 1 and 3, resulting in a cross-sectional area of $11745.35 \mathrm{~mm}^{2}$ and a void percentage of 45.62. On the other hand, ten (10) bamboo rings of $\varnothing 45 \mathrm{~mm}$ are used in E.C. 2 and 4, resulting in a cross-sectional area of $8929.66 \mathrm{~mm}^{2}$ and a void percentage of 55.90. The core configuration in the

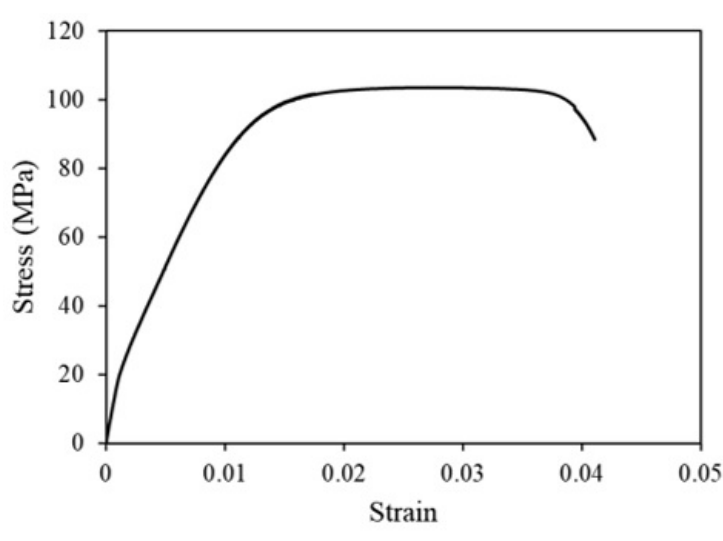

Figure 4. Stress-strain curve for the aluminium alloy.

middle of the sandwich panel is different between conditions. In E.C. 1 and 3, the force is applied in the interface of six (6) $\varnothing 30 \mathrm{~mm}$ bamboo rings, while in E.C. 2 and 4, the force is applied in the middle of two (2) Ø45 $\mathrm{mm}$ bamboo rings. This fact leads to different moment of inertia of area in the middle of the panels, which can also affect the bending rigidity of the structure. This issue will be further discussed in section 3.4.

\subsection{Statistical design}

Table 5 presents the DoE/ANOVA analysis. The significant effects $(P$-value $\leq 0.05)$ are underlined and those in bold (superior order) will be interpreted via effect plots, illustrating 
Table 5. Analysis of variance (ANOVA).

\begin{tabular}{lccccccc}
\hline & \multicolumn{9}{c}{ P-value $\leq 0.05$} \\
\cline { 2 - 9 } & $\begin{array}{c}\text { Equivalent } \\
\text { Density }\end{array}$ & $\begin{array}{c}\text { Maximum } \\
\text { Load }\end{array}$ & $\begin{array}{c}\text { Flexural } \\
\text { Strength }\end{array}$ & $\begin{array}{c}\text { Flexural } \\
\text { Modulus }\end{array}$ & Skin Stress & $\begin{array}{c}\text { Core Shear } \\
\text { Stress }\end{array}$ & $\begin{array}{c}\text { Core Shear } \\
\text { Modulus }\end{array}$ \\
\hline Treatment (T) & 0.905 & $\mathbf{0 . 0 0 2}$ & $\mathbf{0 . 0 0 0}$ & 0.000 & $\mathbf{0 . 0 0 6}$ & 0.000 & 0.000 \\
\hline Diameter (D) & $\mathbf{0 . 0 1 1}$ & $\mathbf{0 . 0 0 5}$ & $\mathbf{0 . 0 0 1}$ & 0.004 & $\mathbf{0 . 0 1 7}$ & 0.001 & 0.004 \\
\hline T x D & 0.100 & 0.094 & 0.393 & $\mathbf{0 . 0 0 5}$ & 0.422 & $\mathbf{0 . 0 4 4}$ & $\mathbf{0 . 0 2 5}$ \\
\hline $\mathrm{R}^{2}$ - adj & $75.57 \%$ & $91.86 \%$ & $97.31 \%$ & $97.57 \%$ & $85.87 \%$ & $97.69 \%$ & $97.93 \%$ \\
\hline Anderson - Darling & 0.990 & 0.082 & 0.898 & 0.686 & 0.435 & 0.288 & 0.640 \\
\hline
\end{tabular}

the statistical design. The $\mathrm{R}_{\text {adj }}^{2}$ (adjusted) parameter varies from 75.57 to $97.93 \%$, indicating good predictability of the statistical model used. Although the $\mathrm{R}_{\text {adj }}^{2}$ for the equivalent density is slightly lower, it still indicates a model of good predictability since $75.75 \%$ of the variability of this response is explained by the factor and the interactions. This reduction is attributed to the "Treatment" factor and "Treatment $x$ Diameter" interaction, which are not significant (P-values $<0.05$ ) and, therefore, contribute to the reduction of $\mathrm{R}^{2}$ adj; The P-values for the Anderson-Darling normality test are greater than 0.05 , which implies the data follow a normal distribution, validating ANOVA.

\subsubsection{Equivalent density}

Figure 5 shows the main effect plot for the mean equivalent density. The treatment of the aluminium surface does not affect the physical characteristics of the panels, since the gain or loss of mass is negligible. Thus, only the diameter factor has a significant effect on the response, exhibiting a significant (albeit small) increase of $2 \%$ for sandwich panels with $\varnothing 30 \mathrm{~mm}$ bamboo rings, which is attributed to the lower percentage of voids (higher structural weight) as shown in Table 4, and greater density of this ring when compared to the $\varnothing 45 \mathrm{~mm}$ (Table 2).

\subsubsection{Maximum load}

Figure 6 exhibits the main effect plot for the mean maximum bending load. Wash primer treated aluminium skins lead to a $10 \%$ increase in the maximum load of the sandwich panels compared to those treated with sodium hydroxide (Figure 6a). According to Oliveira et al. ${ }^{20}$ and Davies ${ }^{45}$, the use of surface primers on metallic skins can provide protection against moisture and corrosion while enhancing the chemical bond between the skin surface and the polymeric adhesive. Therefore, the increase in this response implies an improvement in the skinpolymer interface adhesion, especially in the plastic region, when the primer is used.

Sandwich panels with $\varnothing 30 \mathrm{~mm}$ bamboo rings exhibit an $8 \%$ increase in maximum load (Figure 6b). The bamboo rings have several vessels for transporting water and sap, oriented parallel to the longitudinal axis, which causes absorption of the polymer by capillarity ${ }^{29}$. Therefore, the greater surface contact area of these panels $\left(11745.35 \mathrm{~mm}^{2}\right)$ compared to those with $\varnothing 45 \mathrm{~mm}$ $\left(8929.66 \mathrm{~mm}^{2}\right)$ results in greater core-face adhesion and, consequently, greater efforts are required under bending loads.

\subsubsection{Flexural properties}

Figure 7 shows the main effect plot for the mean flexural strength, which shows similar results for the maximum

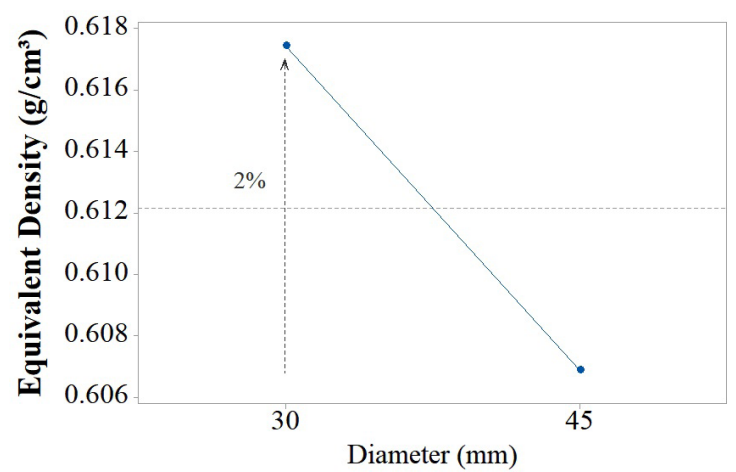

Figure 5. Main effect plot for the mean equivalent density.

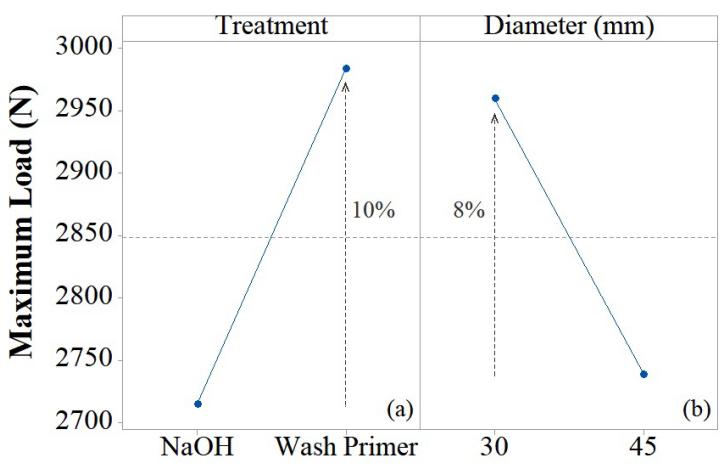

Figure 6. Main effect plots for the mean maximum load.

bending load. Increases of $11 \%$ and $8 \%$ are observed for sandwich panels with wash primer and $\varnothing 30 \mathrm{~mm}$ bamboo rings, respectively, attributed to the efficient adhesion between the phases during the plastic regime and greater surface contact area. On the other hand, Ø45 $\mathrm{mm}$ sandwich panels have two bamboo rings located in the middle of the panel, where force is applied (see Table 4), which contributes to the reduction of flexural strength due to the lower properties of the bamboo in the transverse direction, taken the panel to a localised fracture, as shown in Figure 8.

Figure 9 shows the opposite behaviour in flexural modulus for $\mathrm{NaOH}$ treated sandwich panels, revealing increases of up to $28 \%$ when compared to the condition with the wash primer. While the treatment with sodium hydroxide consists of removing the unstable aluminium oxide/hydroxide film and cleaning the oils and greases from the bonding surfaces ${ }^{46}$, the use of wash primer creates a thin layer on the aluminium surface, allowing a greater relative deformation between the phases, which increases the flexibility of the panel. 


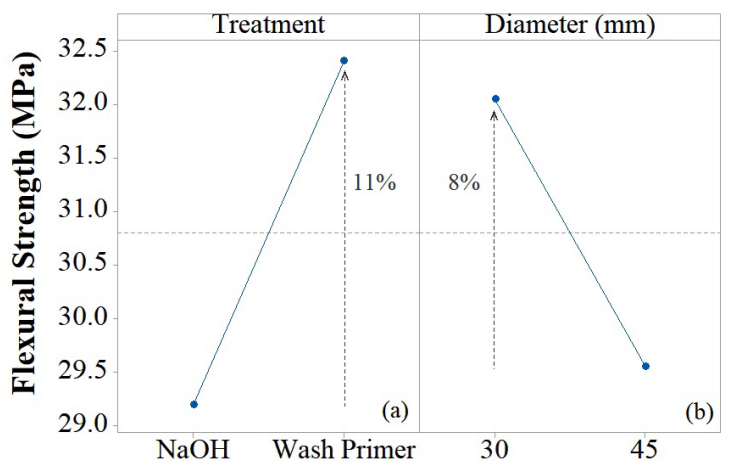

Figure 7. Main effect plots for the mean flexural strength.

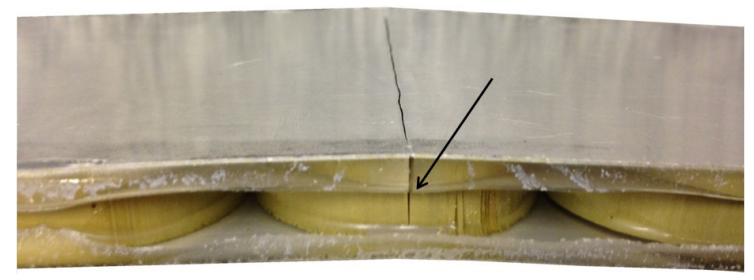

Figure 8. Bamboo fracture achieved for $\varnothing 45 \mathrm{~mm}$ panels.

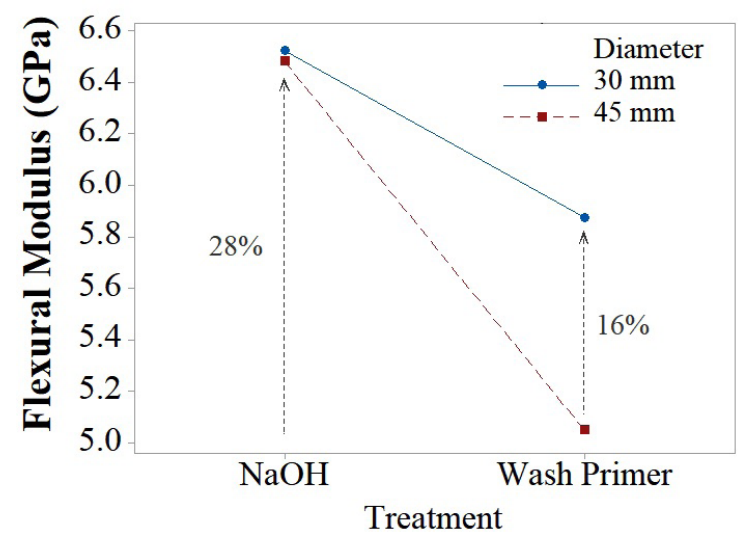

Figure 9. Second order interaction effect plot for the mean flexural modulus.

Panels made with $\varnothing 30 \mathrm{~mm}$ bamboo rings also result in a greater flexural modulus when considered a wash primer, being attributed to the greater amount of bamboo rings per area and, consequently, to the greater number of constraints on the core, requiring more efforts to bend the panel and displace the rings.

\subsubsection{Skin stress}

Figure 10 shows the main effect plots for the mean skin stress of the sandwich panels. The results are similar to that of the maximum load, since this response assumes that the facings withstand the full bending load ${ }^{17}$. Increases of $6 \%$ and $5 \%$ are noted in sandwich panels made with aluminium treated with wash primer (Figure 10a) and $\varnothing 30 \mathrm{~mm}$ bamboo rings (Figure 10b), respectively, attributed to the efficient adhesion between the phases and greater surface contact area.

The skin stresses are above the ultimate tensile strength of the aluminium sheet $(103.5 \mathrm{MPa})$, resulting in a skin fracture for all experimental conditions, as will be shown

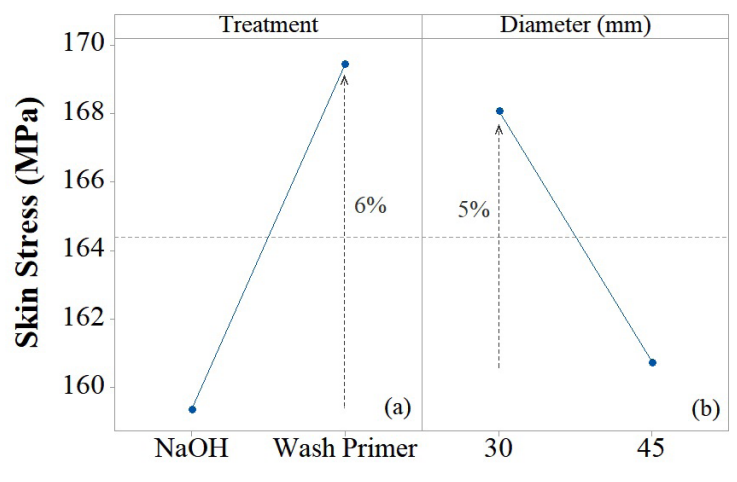

Figure 10. Main effect plot for the mean skin stress.

in Section 3.4. This fact implies a good core-adhesive and adhesive-face bond due to the high absorption of the polymer by the bamboo rings and the efficient surface treatment carried out on aluminium, respectively.

\subsubsection{Core shear properties}

Figures 11 and 12 show the second-order interaction effect plot for the mean core shear stress and modulus, respectively. The use of $\varnothing 30 \mathrm{~mm}$ bamboo rings shows superior results for both responses, exhibiting increases of up to $14 \%$ and $40 \%$ for core shear stress and modulus, respectively. Similar results are observed by Oliveira et al. ${ }^{47}$, in which smaller bamboo diameters require more shearing efforts due to the greater number of bamboo rings per area and the lower percentage of voids, resulting in a greater number of in-plane constraints.

Sandwich panels with $\varnothing 45 \mathrm{~mm}$ bamboo rings and wash primer-treated aluminium skins exhibit a $20 \%$ increase in core shear stress (Figure 11), while those with sodium hydroxide exhibit a 19\% increase in core shear modulus (Figure 12). The use of a wash primer provides a more flexible coreskin interface, which explains its improved behaviour for the core shear stress response. In contrast, the removal of a thin oxide/hydroxide layer from the aluminum surface with $\mathrm{NaOH}$ makes the interfacial adhesion more rigid, compromising the plastic shear strains of the core, leading to a greater core shear modulus.

\subsection{Failure analysis}

Figure 13 shows the typical force versus displacement curves for the experimental conditions obtained by the threepoint bending test. All sandwich panels have a short elastic deformation followed by load reduction in the nonlinear region due to the beginning of cracks between the adhesive and the skins. Subsequently, the increase in displacement causes a progressive failure, resulting in a sudden drop with the rupture of the bottom skin due to tensile stresses (Figure 13). Wash primer sandwich panels (E.C. 3 and 4) lead to greater toughness attributed to more flexible interfacial adhesion compared to $\mathrm{NaOH}$ treatment.

The sandwich panels made with $\varnothing 45 \mathrm{~mm}$ bamboo reveal not only the skin, but also bamboo fractures located in the region of the applied force, as shown in Figure 14. This behaviour can be attributed to the greater displacement of the lower skin under tensile loads and the strong face-core bonding interface that radially stretches the bamboo ring. 
In addition, the bending moment applied to the longitudinal cross-section of the bamboo also contributes to propagate the crack transversely. It is noteworthy that this fracture does not affect the sandwich toughness, as shown in Figure 13. This failure mode is not observed in sandwich panels with $\varnothing 30 \mathrm{~mm}$ bamboo rings, since the force is applied at the cell interface.

It is worth mentioning that the moment of inertia of area plays an important role in the bending rigidity and strength of the panels. As shown in Table 4, and previously

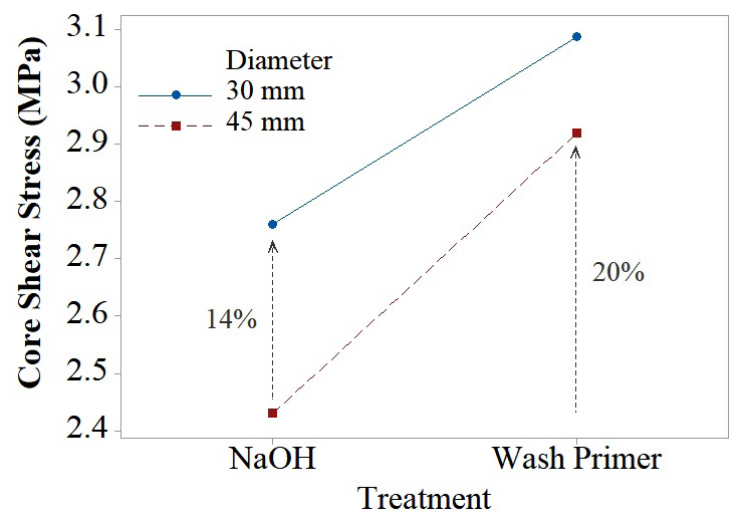

Figure 11. Second-order interaction effect plot for the core shear stress.

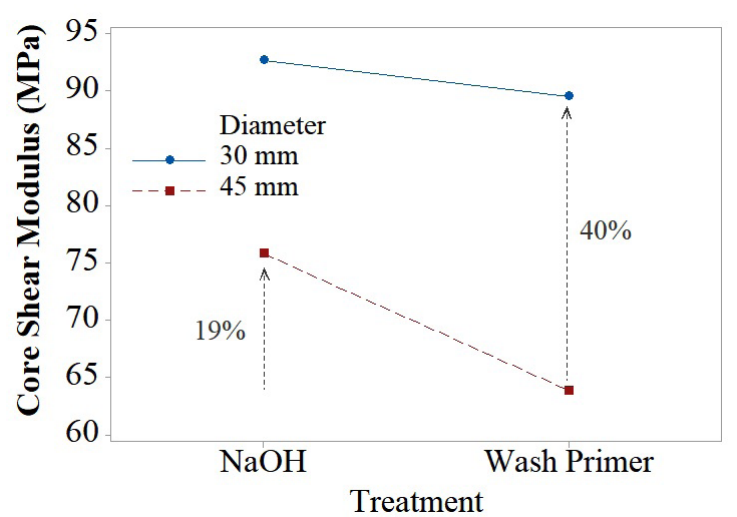

Figure 12. Second-order interaction effect plot for the core shear modulus. mentioned, $\varnothing 30 \mathrm{~mm}$ bamboo rings lead to a cell interface in the middle of the panel, while $\varnothing 45 \mathrm{~mm}$ bamboo rings are positioned through the centre. It would be expected that the latter would lead to an increase in stiffness or strength; however, the opposite occurred (Figures 7 and 9), which demonstrates that the mechanical performance of the panel depends mainly on the adhesiveness of its components, that is, the greater contact area, the greater the strength and stiffness of the panels.

\subsection{Comparison to other core type}

The properties of the proposed bamboo core panels are compared with sustainable sandwich structures made from bottle caps core and aluminium skins, developed by Oliveira et al. ${ }^{20}$ for secondary structural applications. The comparison is made with the experimental condition $\mathrm{C} 3$ in both studies, since the similar configuration is considered, such as cell diameter (30 mm); aluminium type (brushed); polymer type (Renlam M/HY951 Hardener); cell packing (cubic) and skin treatment (wash primer). Both structures were manufactured in a similar way, using cold compaction pressure.

Table 6 shows the overall properties of the panels and their respective specific properties (absolute properties divided by density). All properties are superior for the sandwich

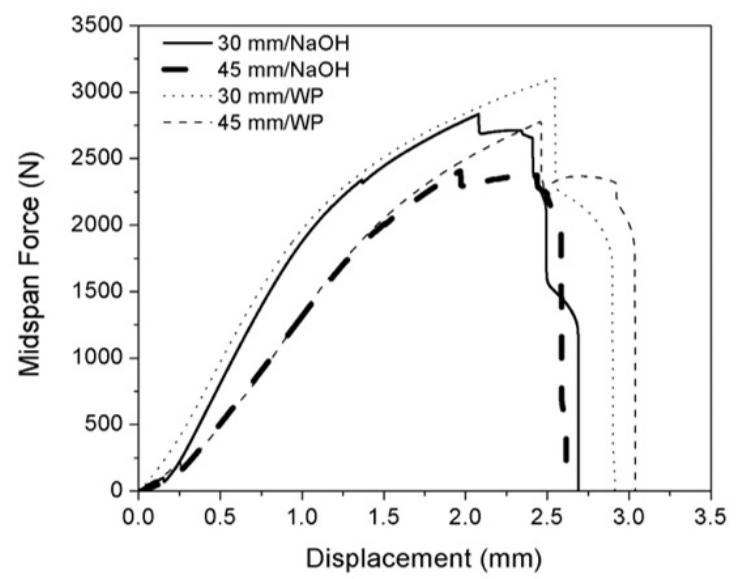

Figure 13. Typical bending behaviour for the sandwich panels.

Table 6. Comparison between the proposed sandwich panels and bottle caps panel.

\begin{tabular}{|c|c|c|c|}
\hline \multirow{2}{*}{ Property } & \multicolumn{2}{|c|}{ Core type } & \multirow{2}{*}{ Percent increase $(\%)$} \\
\hline & Bamboo & Bottle caps ${ }^{20}$ & \\
\hline Equivalent Density $\left(\mathrm{g} / \mathrm{cm}^{3}\right)$ & 0.62 & 0.59 & 5.1 \\
\hline Maximum Load $(\mathrm{N})$ & 3144 & 2111 & 48.9 \\
\hline Flexural Strength $(\mathrm{MPa})$ & 33.8 & 27.2 & 24.2 \\
\hline Specific Flexural Strength (N.m.g $\left.{ }^{-1}\right)$ & 54.5 & 46.1 & 18.2 \\
\hline Flexural Modulus $(\mathrm{GPa})$ & 5.88 & 2.83 & 107.8 \\
\hline Specific Flexural Modulus (kN.m.g-1) & 9.5 & 4.8 & 97.7 \\
\hline Skin Stress (MPa) & 174.0 & 129.2 & 34.6 \\
\hline Specific Skin Stress (N.m.g ${ }^{-1}$ ) & 280.6 & 219.0 & 28.1 \\
\hline Core Shear Stress (MPa) & 3.08 & 0.86 & 258.1 \\
\hline Specific Core Shear Stress (N.m.g $\left.{ }^{-1}\right)$ & 5.0 & 1.5 & 240.8 \\
\hline Core Shear Modulus (MPa) & 90 & 30 & 198.5 \\
\hline Specific Core Shear Modulus (N.m.g $\left.{ }^{-1}\right)$ & 144.4 & 50.8 & 184.0 \\
\hline
\end{tabular}



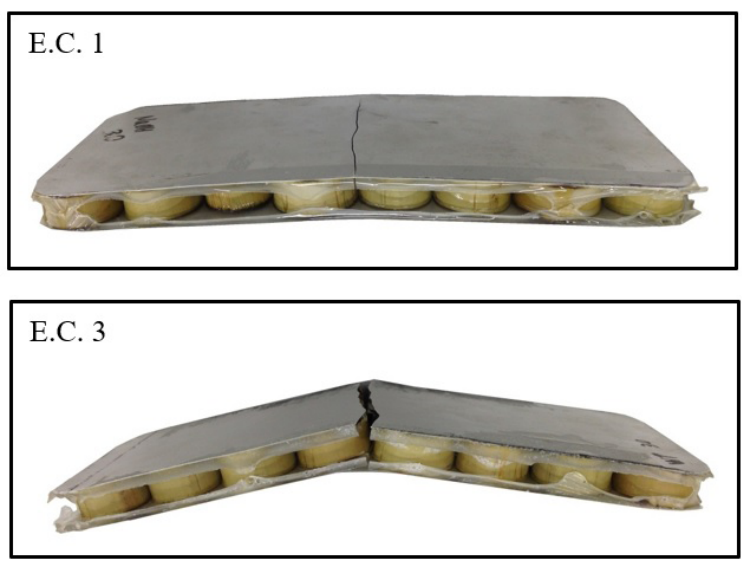

Figure 14. Failure mode of the sandwich panels for each experimental condition.

panel made with bamboo core, revealing increments of up to $258.14 \%$. This increase is attributed to the high elastic modulus of the bamboo rings (12.1 against $1.01 \mathrm{GPa}^{10}$ ) and their greater adhesion to the epoxy polymer, requiring more efforts to deform and fracture the panel.

Finally, the use of bamboo rings as a core material in sandwich panels, in addition to sustainable and economic issues, revealed good mechanical performance, resulting in a feasible and promising alternative in the replacement of secondary structural components in various fields, such as transportation facilities, civil infrastructure, cargo bays and others.

\section{Conclusions}

This work describes the mechanical behaviour of a sandwich panel composed of bamboo rings as a circular honeycomb core, treated aluminium skins and epoxy adhesive. The effect of the aluminium treatment and bamboo diameter on the equivalent density, flexural and shear properties of the panels is identified through a statistical design. The main conclusions from the present work are:

i. Primed-aluminium skins provide more flexible adhesion to the skin-core, leading to greater maximum load, flexural strength, skin stress and core shear stress. Otherwise, aluminium treated with $\mathrm{NaOH}$ leads to a more rigid skin-core adhesion, resulting in a greater flexural and core shear modulus.

ii. Relatively more rigid and resistant structures are obtained with $\varnothing 30 \mathrm{~mm}$ bamboo rings attributed to the increased surface contact area and the number of constraints in the core.

iii. All experimental conditions fail due to skin fracture, implying an efficient face-core bond, attributed to the proper absorption of the polymer by the bamboo rings and the superficial treatment of aluminium. Cracks along the bamboo rings are evident only for diameters of $45 \mathrm{~mm}$.

iv. Bamboo panels achieve a substantial increase in all absolute and specific physical-mechanical properties when compared to panels made with a bottle cap core, being a sustainable and promising alternative for structural applications.

\section{Acknowledgments}

The authors would like to thank the Brazilian Research Agencies, CAPES (PhD scholarship) and CNPq (PQ 309885/2019-1) for the financial support provided.

\section{References}

1. Wang Z, Li Z, Xiong W. Experimental investigation on bending behavior of honeycomb sandwich panel with ceramic tile face-sheet. Compos Part B. 2019;164:280-6. http://dx.doi. org/10.1016/j.compositesb.2018.10.077.

2. Hu LL, He XL, Wu GP, Yu TX. Dynamic crushing of the circular-celled honeycombs under out-of-plane impact. Int J Impact Eng. 2015;75:150-61. http://dx.doi.org/10.1016/j. ijimpeng.2014.08.008.

3. Wang Z, Liu J, Hui D. Mechanical behaviors of inclined cell honeycomb structure subjected to compression. Compos, Part B Eng. 2017;110:307-14. http://dx.doi.org/10.1016/j. compositesb.2016.10.062.

4. Wang Z, Li Z, Zhou W, Hui D. On the influence of structural defects for honeycomb structure. Compos, Part B Eng. 2018;142:18392. http://dx.doi.org/10.1016/j.compositesb.2018.01.015.

5. Cabrera NO, Alcock B, Peijs T. Design and manufacture of all-PP sandwich panels based on co-extruded polypropylene tapes. Compos, Part B Eng. 2008;39:1183-95. http://dx.doi. org/10.1016/j.compositesb.2008.03.010.

6. Gholami M, Alashti RA, Fathi A. Optimal design of a honeycomb core composite sandwich panel using evolutionary optimization algorithms. Compos Struct. 2016;139:254-62. http://dx.doi. org/10.1016/j.compstruct.2015.12.019.

7. Wang J, Shi C, Yang N, Sun H, Liu Y, Song B. Strength, stiffness, and panel peeling strength of carbon fiber-reinforced composite sandwich structures with aluminum honeycomb cores for vehicle body. Compos Struct. 2018;184:1189-96. http://dx.doi.org/10.1016/j.compstruct.2017.10.038.

8. Gotkhindi TP, Simha KRY. In-plane effective shear modulus of generalized circular honeycomb structures and bundled tubes in a diamond array structure. Int J Mech Sci. 2015;101:292-308. http://dx.doi.org/10.1016/j.ijmecsci.2015.08.009.

9. Allen HG. Analysis and design of structural sandwich panels. Reino Unido: Pergamon Press; 1969.

10. D'Mello RJ, Waas AM. Synergistic energy absorption in the axial crush response of filled circular cell honeycombs. Compos Struct. 2012;94:1669-76. http://dx.doi.org/10.1016/j. compstruct.2011.12.009. 
11. Feng Y, Qiu H, Gao Y, Zheng H, Tan J. Creative design for sandwich structures: a review. Inter J Adv Robot Syst. 2020:124. http://dx.doi.org/10.1177/1729881420921327.

12. Huang J, Gong X, Zhang Q, Scarpa F, Liu Y, Leng J. In-plane mechanics of a novel zero Poisson's ratio honeycomb core. Compos, Part B Eng. 2016;89:67-76. http://dx.doi.org/10.1016/j. compositesb.2015.11.032.

13. Huang J, Zhang Q, Scarpa F, Liu Y, Leng J. In-plane elasticity of a novel auxetic honeycomb design. Compos, Part B Eng. 2018;110:72-82.http://dx.doi.org/10.1016/j.compositesb.2016.11.011.

14. Cai Z-Y, Zhang X, Liang X-B. Multi-point forming of sandwich panels with egg-box-like cores and failure behaviors in forming process: analytical models, numerical and experimental investigations. Mater Des. 2018;160:1029-41. http://dx.doi. org/10.1016/j.matdes.2018.10.037.

15. Lee B-C, Lee K-W, Byun J-H, Kang K-J. The compressive response of new composite truss cores. Compos, Part B Eng. 2012;43:31724. http://dx.doi.org/10.1016/j.compositesb.2011.08.048.

16. Bitzer T. Honeycomb technology: materials, design, manufacturing, applications and testing. USA: Springer; 1997.

17. Oruganti RK, Ghosh AK. FEM analysis of transverse creep in honeycomb structures. Acta Mater. 2008;56:726-35. http:// dx.doi.org/10.1016/j.actamat.2007.10.019.

18. Karagiozova D, Yu TX. Post-collapse characteristics of ductile circular honeycombs under in-plane compression. Int J Mech Sci. 2005;47:570-602. http://dx.doi.org/10.1016/j. ijmecsci.2004.11.011.

19. Lin TC, Chen TJ, Huang JS. In-plane elastic constants and strengths of circular cell honeycombs. Compos Sci Technol. 2012;72:13806. http://dx.doi.org/10.1016/j.compscitech.2012.05.009.

20. Oliveira PR, Panzera TH, Freire RT, Scarpa F. Sustainable sandwich structures made from bottle caps core and aluminium skins: a statistical approach. Thin-Wall Struct. 2018;130:36271. http://dx.doi.org/10.1016/j.tws.2018.06.003.

21. Kinloch AJ, Lee JH, Taylor AC, Sprenger S, Eger C, Egan D. Toughening structural adhesives via nano- and microphase inclusions. J Adhes. 2003;79:867-73. http://dx.doi. org/10.1080/00218460309551.

22. Ghavami K. Bamboo as reinforcement in structural concrete elements. Cement Concr Compos. 2005;27:637-49. http:// dx.doi.org/10.1016/j.cemconcomp.2004.06.002.

23. Lo TY, Cui HZ, Tang PWC, Leung HC. Strength analysis of bamboo by microscopic investigation of bamboo fibre. Constr Build Mater. 2008;22:1532-5. http://dx.doi.org/10.1016/j. conbuildmat.2007.03.031.

24. Li H-T, Su J-W, Zhang Q-S, Deeks AJ, Hui D. Mechanical performance of laminated bamboo column under axial compression. Compos, Part B Eng. 2015;79:374-82. http:// dx.doi.org/10.1016/j.compositesb.2015.04.027.

25. Krause JQ, Silva FA, Ghavami K, Gomes OFM, Toledo RD Fo. On the influence of Dendrocalamus giganteus bamboo microstructure on its mechanical behaviour. Constr Build Mater. 2016;127:199-209. http://dx.doi.org/10.1016/j. conbuildmat.2016.09.104.

26. Li W-T, Long Y-1, Huang J, Lin Y. Axial load behavior of structural bamboo filled with concrete and cement mortar. Constr Build Mater. 2017;148:273-87. http://dx.doi.org/10.1016/j. conbuildmat.2017.05.061.

27. Chung KF, Yu WK. Mechanical properties of structural bamboo for bamboo scaffoldings. Eng Struct. 2002;24:429-42. http:// dx.doi.org/10.1016/S0141-0296(01)00110-9.

28. Saikia P, Dutta D, Kalita D, Bora JJ, Goswami T. Improvement of mechano-chemical properties of bamboo by bio-chemical treatment. Constr Build Mater. 2015;101:1031-6. http://dx.doi. org/10.1016/j.conbuildmat.2015.10.106.
29. Gottron J, Harries KA, Xu Q. Creep behaviour of bamboo. Constr Build Mater. 2014;66:79-88. http://dx.doi.org/10.1016/j. conbuildmat.2014.05.024.

30. Puri V, Chakrabortty P, Anand S, Majumdar S. Bamboo reinforced prefabricated wall panels for low cost housing. J Build Eng. 2017;9:52-9. http://dx.doi.org/10.1016/j.jobe.2016.11.010.

31. Jakovljevic S, Lisjak D, Alar Z, Penava F. The influence of humidity on mechanical properties of bamboo for bicycles. Constr Build Mater. 2017;150:35-48. http://dx.doi.org/10.1016/j. conbuildmat.2017.05.189.

32. Chee SS, Jawaid M, Sultan MTH, Alothman OY, Abdullah LC. Thermomechanical and dynamic mechanical properties of bamboo/woven kenaf mat reinforced epoxy hybrid composites. Compos, Part B Eng. 2019;163:165-74. http://dx.doi.org/10.1016/j. compositesb.2018.11.039.

33. Hartoni FJ, Anshari B, Catur AD. Effect of core and skin thicknesses of bamboo sandwich composite on bending strength. Int J Mech Eng Tech. 2017;8:551-60.

34. Darzi S, Karampour H, Gilbert BP, Baillers H. Numerical study on the flexural capacity of ultra-light composite timber sandwich panels. Compos, Part B Eng. 2018;155:212-24. http://dx.doi. org/10.1016/j.compositesb.2018.08.022.

35. Sherwin-Williams, Automotive Finishes. [Internet]. Wash Primer Fosfatizante 045. São Paulo: Sherwin-Williams, Automotive Finishes; 2020 [cited 2018 Nov 1]. Available from: https:// www.sherwin-auto.com.br/produtos/complementos/washprimer-fundo-fosfatizante-045/

36. ASTM International. ASTM E8/E8M-16a: standard test method for tension testing of metallic materials. West Conshohocken: ASTM International; 2016.

37. ISO: International Organization for Standardization. ISO 22157-1: Bamboo - determination of physical and mechanical properties - part 1: requirements. Genebra: ISO; 2004.

38. ISO: International Organization for Standardization. ISO 22157-2: Bamboo - determination of physical and mechanical properties - part 2: laboratory manual. Genebra: ISO; 2004.

39. ASTM International. ASTM D790-17: standard test methods for flexural properties of unreinforced and reinforced plastics and electrical insulating materials. West Conshohocken: ASTM International; 2017.

40. ASTM International. ASTM C393/C393M-16: standard test method for core shear properties of sandwich constructions by beam flexure. West Conshohocken: ASTM International; 2016.

41. ASTM International. ASTM D7250/D7250M-16: standard practice for determining sandwich beam flexural and shear stiffness. West Conshohocken: ASTM International; 2016.

42. Oliveira PR, Santos JC, Ribeiro SLM Fo., Ferreira BT, Panzera TH, Scarpa F. Eco-friendly sandwich panel based on recycled bottle caps core and natural fibre composite facings. Fibers Polym. 2020;21:1798-807. http://dx.doi.org/10.1007/s12221020-9818-7.

43. Oliveira PR, Silva LJ, Pino GG, Scarpa F. Transverse fastening reinforcement of sandwich panels with upcycled bottle caps core. J Compos Mater. 2020;55:1-9. http://dx.doi. org/10.1177/0021998320960522.

44. Xu Q, Harries K, Li X, Liu Q, Gottron J. Mechanical properties of structural bamboo following immersion in water. Eng Struct. 2014;81:230-9. http://dx.doi.org/10.1016/j.engstruct.2014.09.044.

45. Davies J. Lightweight sandwich construction. Oxford: Blackwell Science; 2001.

46. Prolongo SG, Ureña A. Effect of surface pre-treatment on the adhesive strength of epoxy-aluminium joints. Int J Adhes Adhes. 2009;29:23-31. http://dx.doi.org/10.1016/j.ijadhadh.2008.01.001.

47. Oliveira LA, Coura GLC, Tonatto MLP, Panzera TH, Placet V, Scarpa F. A novel sandwich panel made of prepreg flax skins and bamboo core. Compos Part C. 2020;3:100048. http://dx.doi. org/10.1016/j.jcomc.2020.100048. 